Original Research Paper

\title{
Thermodynamic Analysis of a Marine Refrigeration Machine with Ammonia
}

\author{
${ }^{1}$ Mawhoub Soubih, ${ }^{2}$ Samir Zahaf, ${ }^{3}$ Dahmane Mouloud and ${ }^{4}$ Benkhettab Mohamed \\ ${ }^{1}$ Labortory of Mechanics and Energy, Chlef University Hassiba Benbouali, Chlef, Algeria \\ ${ }^{2}$ Department of Technology, University of Djilali Bounaama-Khamis Meliana, Ain Defla-Algeria \\ ${ }^{3}$ LMA, Department of Mechanical Engineering, USTO-MB, BP 1055 El Menaour, Oran 31000, Algeria \\ ${ }^{4}$ Department of Mechanical Engineering, Mostaganem University-Abdelhamid Ibn Badis, Algeria
}

\section{Article history}

Received: 02-09-2021

Revised: 21-10-2021

Accepted: 25-10-2021

Corresponding Author:

Samir Zahaf

Department of Technology,

University of Djilali

Bounaama-Khamis Meliana,

Ain Defla-Algeria

Email: samir.zahaf@univ-dbkm.dz

\begin{abstract}
The purpose of this study is to present a thermodynamic modeling of a marine chiller using ammonia as a refrigerant. The modeling is based on the first and second laws of thermodynamics and the fundamental laws of heat transfer. System performance in terms of coefficient of performance, total exergy losses and exegetic efficiency, have calculated the temperatures of sea water and air in puts, respectively, of the condenser and evaporator and their exchange surfaces. The thermodynamic properties of the refrigerant were calculated using simple and reliable state equations. The results showed that the exergy efficiency can, in some cases; do not follow the behavior of the coefficient of performance. In this study, a thermodynamic modeling of a marine refrigeration machine using ammonia as refrigerant was presented. The results showed that the performance of the machine increases as the temperature of the air entering the evaporator increases. On the other hand, an increase in the temperature of the sea water decreases this performance. In addition, the increased surfaces of the heat exchangers (condenser and evaporator) increase the performance of the machine because the formula for the quantity of heat exchanged with the external environment is $\mathrm{Q}=\mathrm{KXSX} \Delta \mathrm{T}(\mathrm{K}$ : Is the heat exchange coefficient, $\Delta \mathrm{T}$ : Is the temperature variation between the two media and S: Is the exchange surface), therefore the larger the surface, the better the exchange, which makes the performance better. In addition, we observe that the exegetical parameters may in some cases not match the COP.
\end{abstract}

Keywords: Modeling, Refrigeration Machine, Ammonia, Exergy, Heat Transfer, Coefficient of Performance (COP)

\section{Introduction}

In the face of growing awareness of environmental and climate issues, the refrigeration industry is still being blamed. There is significant anxiety due to the influence of greenhouse gases on the environment. Indeed, many refrigerants, supposedly replaced CFCs and HCFCs with the "ecological" label, are nowadays incriminated in contributing to the worsening of the greenhouse effect. These new fluids, composed mainly of HFCs compounds, were put by the Kyoto Protocol in the basket of greenhouse gases. Hence the need to find alternatives in order to completely preserve the environment. This situation mobilized the international community to work to reconsider

The use of natural fluids, abandoned in the $1930 \mathrm{~s}$, such as ammonia, $\mathrm{CO}_{2}$, hydrocarbons, air and water vapor. Of these, only ammonia has resisted CFCs and HCFCs, especially in industrial applications. Technological developments in the field of compact heat exchangers are opening up voices to other applications for this fluid.

Ammonia was one of the first fluids used in refrigeration. The main advantage of this fluid is to be neutral from an environmental point of view. Unlike CFCs, it does not destroy the ozone layer and does not contribute to the greenhouse effect. It's high calorific efficiency, its low power input and last but not least, its low cost, have made it an attractive gas from an economic point of view. Our work has shown that ammonia is more efficient than R134a, by carrying out a thermodynamic study between the two fluids for the same refrigeration machine. it has been shown that the COP (coefficient of performance of ammonia is higher than that of R134a). The use of ammonia as a refrigerant helps protect the environment. In addition, ammonia quickly breaks down into its natural components nitrogen and hydrogen, preventing any danger to the climate through a direct greenhouse effect. 
For all these different reasons, he established that ammonia, through its yield, its worldwide abundance and its ecological properties, is a fluid of the future. Although this fluid is fully accepted by the environment, it has two major drawbacks: Toxicity and flammability. These disadvantages can be reduced by reducing its load in refrigeration systems. This is possible by the use of compact heat exchangers. This prompted the governments of various countries to adopt new regulations concerning the field of refrigeration installations employing ammonia.

Many researchers argue for a more varied use of ammonia in order to benefit from this performance in other applications such as commercial, domestic, transport and marine refrigeration. In the latter, it can be used alone in a single or two-stage cycle or associated with another natural fluid, $\mathrm{CO}_{2}$, in cascade machines. These applications require the availability of thermodynamic models making it possible to simulate the operation of the systems in order to find the optimum operating parameters. There is a multitude of models in the literature based on the fundamental laws of physics as well as empirical correlations.

The benefits of using ammonia in industrial applications are well known (Kortitsen and Kristensen, 1998). Current studies are moving towards new applications of this natural fluid. Stera (1994) presented a study on the substitution of HCFC22 by ammonia for marine applications. He presented a comparison of the performance of the two refrigerants for different operating conditions of refrigeration systems, as he presented the preventive measures to be taken into account when using ammonia in order to avoid the risk of leaks and d 'fire. In an economic study on the consequences of replacing CFCs, Aisbett and Pham (1998) concluded that the switch to HFCs requires heavy investments compared to natural fluids for the countries of South Asia. Kortitsen and Kristensen (1998) evaluated the use of ammonia as a refrigerant in industrial heat pumps. They have developed compressors operating at high pressures of up to 40 bars. The characteristics and operating conditions have been presented for the studied case. Palm (2008) developed a prototype of a domestic water-to-water heat pump with a heating capacity of $9 \mathrm{~kW}$.

He has shown that this system can operate with only $100 \mathrm{~g}$ of ammonia as a refrigerant. However, he noted the existence of lubricating oil issues and the lack of hermetic or semi-hermetic compressors for ammonia within this range. For his part, Pearson (2008), in a review article, explained the reasons for the popularity of ammonia in industrial applications and its refusal in other applications. He also suggested applications in which ammonia can be used provided regulations change locally and internationally. Majgaonkar (2008) described the many additional constraints faced by a designer of a marine refrigeration machine. The constraints concerned the calculation of the cooling capacity, the choice of refrigerant, the limit of space and safety. For cascade applications, for low temperature requirements, the new systems combine $\mathrm{CO}_{2}$ with ammonia (Ouadha et al., 2007; Getu and Bansal, 2008).

\section{Thermodynamic Properties}

The calculation and simulation of refrigeration systems require the availability of simple and reliable mathematical models for the determination of the thermodynamic properties of refrigerants.

Thermodynamic properties are needed at key points in the cycle and along the processes taking place in the various components of the system. The choice of the thermodynamic model is mainly dictated by the concern for rigor, reliability and validity in the operating field considered. The model retained for the description of the thermodynamic properties of ammonia is based on four local equations of state (Calise et al., 2013) .

- An equation of state of the gas phase, expressing the compressibility coefficient as a function of the inverse of the reduced temperature $(\theta)$ and the reduced density $(\omega)$ :

$$
Z=Z(\theta, \omega)
$$

An equation of the saturation pressure as a function of the reduced temperature $\left(T_{r}\right)$ :

$$
P_{s}=P_{s}\left(T_{r}\right)
$$

An equation of the density of the saturated liquid as a function of the reduced temperature $(\mathrm{Tr})$ :

$$
P_{L}=P_{L}\left(T_{r}\right)
$$

An equation of the specific heat at constant pressure in the ideal gas state as a function of the reduced temperature $\left(T_{r}\right)$ :

$C_{p}^{o}=C_{p}^{o}\left(T_{r}\right)$

Using the equations from (1) to (4) and the differential equations of thermodynamics, it is possible to calculate the thermodynamic properties necessary for the analysis of refrigeration systems, namely enthalpy, entropy and exergy.

\section{Thermodynamic Modeling}

\section{System Description}

Figure 1 shows the system considered in the present study. It consists of a single-stage vapor compression refrigeration machine comprising a compressor, a condenser, an expansion device and an evaporator.

The refrigerant, in the state of superheated vapor, enters the compressor where it is compressed to reach condensing pressure. High pressure superheated vapors enter the condenser, where they are desuperheated and condensed. The refrigerant is sub-cooled before being expanded to the evaporator. Finally, the refrigerant enters 
the evaporator, where it absorbs heat. Before entering the compressor again, the refrigerant is superheated by absorbing more heat in the suction line.

An internal heat exchanger (recuperator) is used to superheat the gases before suction while sub-cooling the condensate upstream of the expansion valve. The incorporation of this heat exchanger generally improves the performance of the system. The condenser is cooled using a seawater circuit while the evaporator is in direct contact with the air in the room to be cooled.

The refrigeration production is calculated by the difference in enthalpy between the outlet and the inlet of the evaporator: h1-h6. While, the work consumed by the compressor represents the difference in enthalpy between the suction and the discharge: h2-h1 $(\mathrm{J} / \mathrm{K})$

\section{Energy Balance}

The entire system was simulated on the basis of energy and heat transfer balances. The energy balance of the refrigeration machine (air-water) is established using the following assumptions:

- Each component of the system is analyzed as a control volume

- The heat losses in the internal exchanger are neglected (all the heat released during the subcooling is recovered for the superheating of the steam before the compressor suction). Thus, only the heat dissipations in the compressor are included

- The pressure drops in the compressor suction and discharge pipes are neglected

- Condensation and evaporation are assumed to be isobaric

The thermal load of the condenser is calculated by:

$$
Q_{\text {cond }}=\left(W-Q_{p}\right)+Q_{e^{\prime} \text { vap }}(\text { Joule })
$$

where, $Q_{p}$ are the heat losses due to the unadiabacity of the compression process. The condenser and evaporator charges can be calculated by the following expressions:

$$
\begin{aligned}
& Q_{\text {cond }}=K_{\text {eau.cond }} \cdot S_{\text {cond }} \cdot D L M T_{\text {cond }}(\text { Joule }) \\
& Q_{\text {cond }}=K_{\text {eau.e'vap }} \cdot S_{\text {cond }} . D L M T_{\text {evap }}(\text { Joule })
\end{aligned}
$$

where, $D L M T_{\text {cond }}$ and $D L M T_{\text {évap }}$ are the average logarithmic temperature differences, respectively, in the condenser and evaporator.

$$
D L M T_{\text {cond }}=\frac{T_{S, \text { cond }}-T_{e, \text { cond }}}{\left[\frac{T_{\text {cond }}-T_{e, \text { cond }}}{T_{\text {cond }}-T_{S, \text { cond }}}\right]}(k / k)
$$

$$
D L M T_{\text {cond }}=\frac{T_{S, e^{\prime} \text { vap }}-T_{e, e^{\prime} \text { vap }}}{\left[\frac{T_{S, e^{\prime} \text { vap }}-T_{e, e^{\prime} v a p}}{T_{S, e^{\prime} \text { vap }}-T_{e^{\prime} \text { vap }}}\right]}(k / k)
$$

The condenser and evaporator charges can also be calculated from the temperature variation of the secondary refrigerant (air, seawater), the mass flow rate and the specific heat capacity of this secondary refrigerant. They are given by:

$Q_{\text {cond }}=\dot{m}_{\text {eau }, \text { cond }} \cdot C_{\text {eau, cond }} \cdot\left(T_{s, \text { cond }}-T_{e, \text { cond }}\right)($ joule $)$

$Q_{e^{\prime} v a p}=\dot{m}_{\text {air }, e^{\prime} v a p} . C_{\text {air }, e^{\prime} v a p} .\left(T_{s, e^{\prime} v a p}-T_{e, e^{\prime} v a p}\right)($ joule $)$

Using the change in the enthalpy of the refrigerant, we obtain:

$$
\begin{aligned}
& Q_{\text {cond }}=\dot{m} \times\left(h_{2}-h_{5}\right)(\text { Joule }) \\
& Q_{\text {cond }} \doteq \times\left(h_{1}-h_{6}\right)(\text { Joule }) \\
& K_{\text {eau, cond }}=\frac{Q_{\text {cond }}}{S_{\text {cond }} D L M T_{\text {cond }}}\left(\mathrm{J} / \mathrm{m}^{2}\right)
\end{aligned}
$$

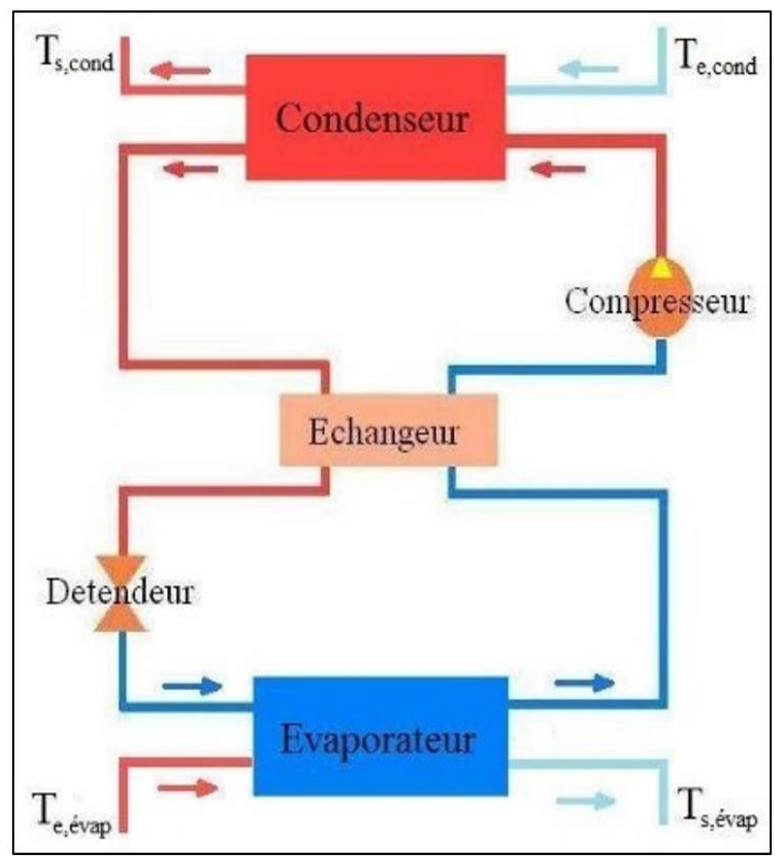

Fig. 1: Diagram of an air-sea water refrigeration machine with an internal heat exchanger 


\section{Results}

A Fortran program has been developed to calculate the condensing temperature $T_{\text {cond }}$ and the performance of the machine. The analysis was performed for a refrigeration machine using ammonia and $\mathrm{R} 134 \mathrm{a}$ as refrigerants. Table 1 shows the basic parameters of the simulation.

\section{Combined Influence of the Air Temperature at the} Inlet of the Evaporator and the Surface of the Condenser

In this case, the inlet temperature of the seawater to the condenser was maintained at $298 \mathrm{~K}$, while the air temperature at the inlet of the evaporator varies from 285 to $293 \mathrm{~K}$. In addition, in the aim of seeing the influence of the condenser surface, the latter is varied from 3 to $10 \mathrm{~m}^{2}$ for an evaporator surface fixed at $4 \mathrm{~m}^{2}$. "Figure 2" show the variation of the Coefficient Of Performance (COP), the total exergetic losses $\left(\Delta E_{e x}, t\right)$ and the exergetic efficiency $\left(\eta_{e x}\right)$ as a function of the temperature of the air entering the evaporator $\left(T_{e, \text { evap }}\right)$ and the surface of the condenser $\left(S_{\text {cond }}\right)$. The increase in the temperature of the air entering the evaporator causes a linear increase in the coefficient of performance. This increase is due to the increase in the amount of cold produced because the variation in the power supplied to the compressor is minimal. However, the exergy parameters do not follow this trend: The exergy losses increase while the exergy efficiency decreases. It is also noticed that the increase of the condenser area brings a marked improvement in the performance of the system.

\section{Combined Influence of the Air Temperature at the Evaporator Inlet and the Evaporator Surface}

In this case, the air inlet temperature to the evaporator was varied from 285 to $293 \mathrm{~K}$ to see the influence of this parameter on the coefficient of performance COP, while the seawater temperature at the condenser inlet was kept at $298 \mathrm{~K}$. In addition, the area of the evaporator was varied from 4 to $8 \mathrm{~m}^{2}$ for a condenser area equal to $8 \mathrm{~m}^{2}$. "Figure 3 " show the variation of the Coefficient Of Performance (COP), the total exergy losses $\left(\Delta E_{e x}, t\right)$ and the exergy efficiency $\left(\eta_{e x}\right)$ as a function of the temperature of the air entering the evaporator $\left(T_{e, \text { evap }}\right)$ and the surface of the evaporator $\left(S_{\text {évap }}\right)$.

It can be seen that the increase in the temperature of the air entering the evaporator also causes a linear increase in $(\mathrm{COP})$. For example, for $\left(T_{e, \text { evap }}=293 \mathrm{~K}\right)$, changing the evaporator surface from 4 to $8 \mathrm{~m}^{2}$ gives a growth of (COP) of $15.90 \%$. It is also noted that the exergy parameters do not follow the behavior of (COP). R717 is clearly higher compared to (COP) of R134a. This behavior can be explained by the increased heat transfer which causes more irreversibility in the system. The increase in the exchange surface of the evaporator increases the (COP) and causes irreversibilities which negatively influence the exergy efficiency.

\section{Combined Influence of the Water Temperature at the Condenser Inlet and the Condenser Surface}

To analyze the influence of the temperature of the secondary refrigerant intended for cooling the condenser, the temperature at the inlet of the evaporator was maintained at $285 \mathrm{~K}$, while the temperature of the water at the inlet of the condenser was varied from $298 \mathrm{~K}$ to 308 $\mathrm{K}$. The values of the condenser area were varied from 3 to $10 \mathrm{~m}^{2}$ to assess their influence on cycle performance for an evaporator area maintained at $4 \mathrm{~m}^{2}$. "Figure 4" show the variation in the Coefficient Of Performance (COP), the total exergy losses $\left(\Delta E_{e x}, t\right)$ and the exergy efficiency $\left(\eta_{e x}\right)$ as a function of the seawater temperature at the inlet of the condenser. The (COP), decreases with increasing $\left(\eta_{e x}\right)$ because the more the exergy losses in a system increase, the more the efficiency decreases, which explains our results. The exergy efficiency and the total losses, on the contrary here, produce the same behavior as the (COP). We also notice that increasing the area of the condenser increases the (COP) and decreasing. These have minimum values that can be useful in the design of the condenser.

There is not much research that directly addresses a comparison between the two refrigerants, Ammonia and R134a. So we can consider that our work is original and that the results obtained are useful especially for the naval industry.

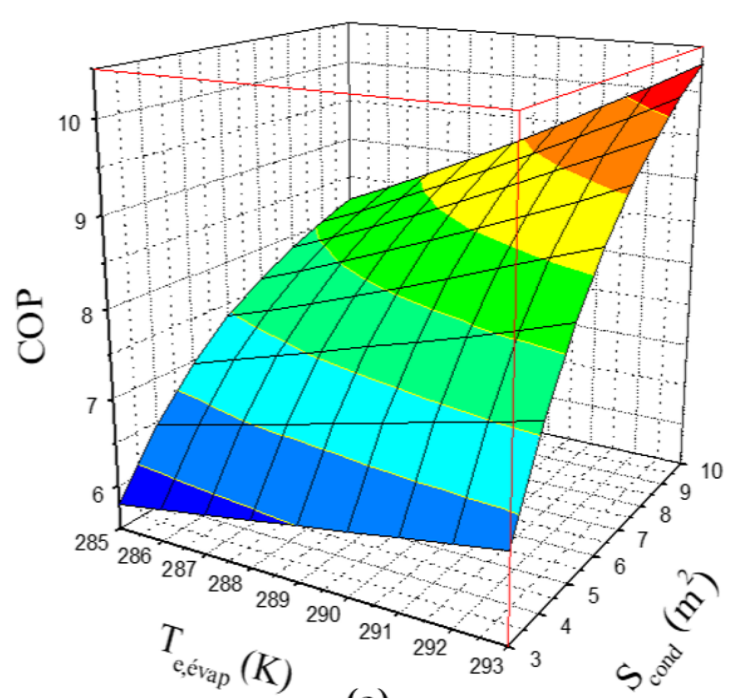

(a) 


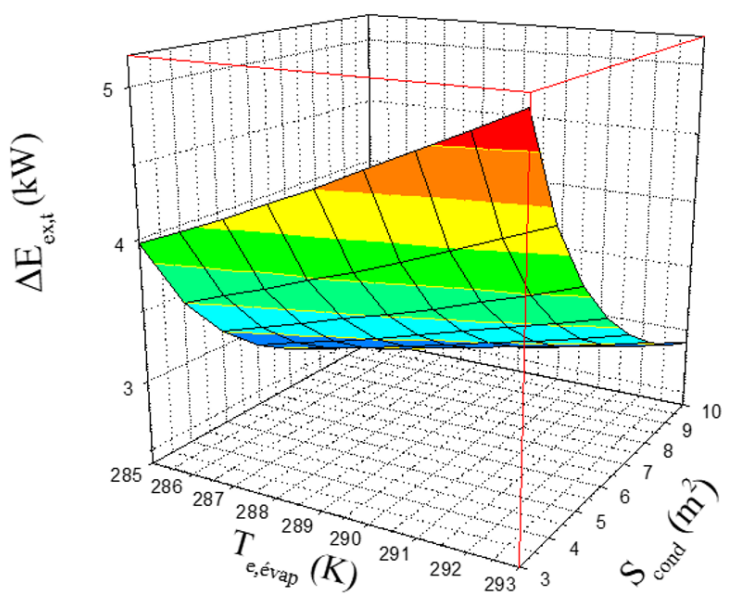

(b)

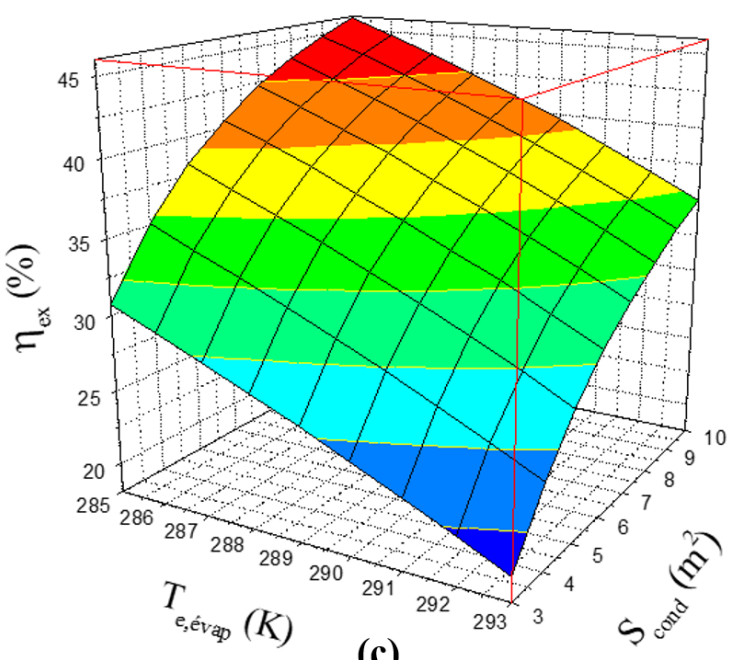

(c)

Fig. 2: Combined influence of the air temperature at the evaporator inlet and the condenser surface on: (a): $C O P$, (b): $\Delta E_{e x}, t,(\mathrm{c}): \eta_{e x}$.

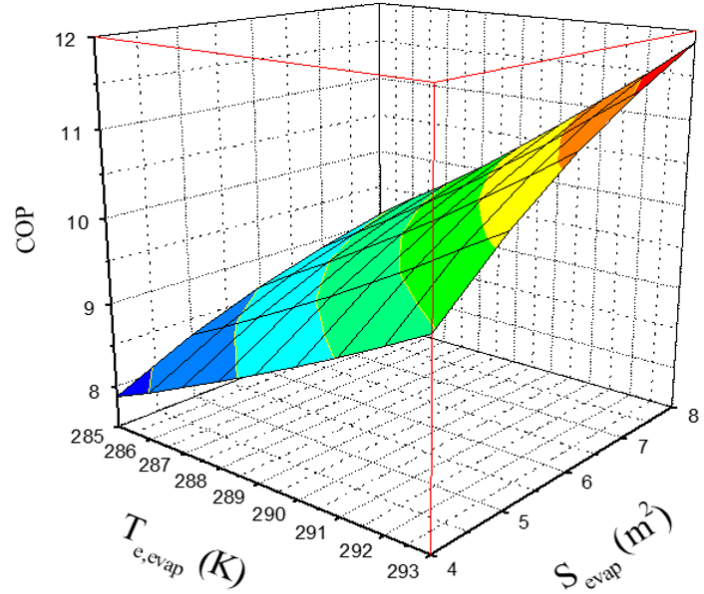

(a)

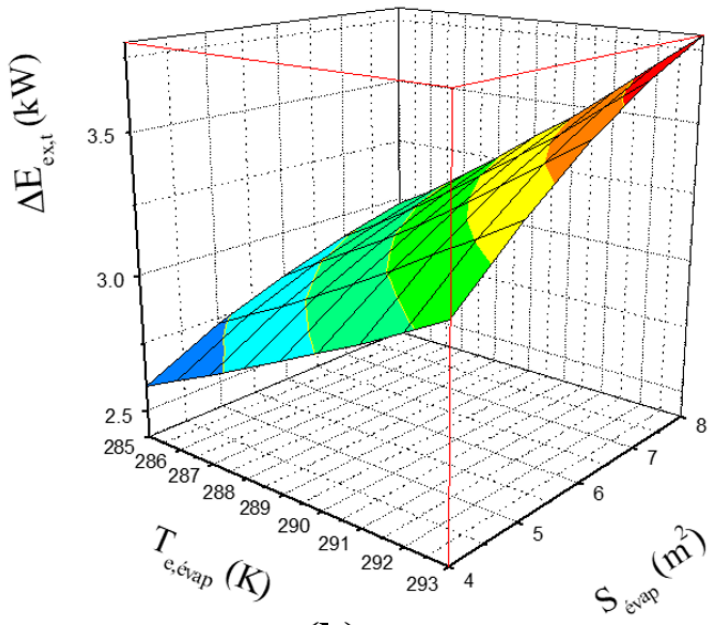

(b)

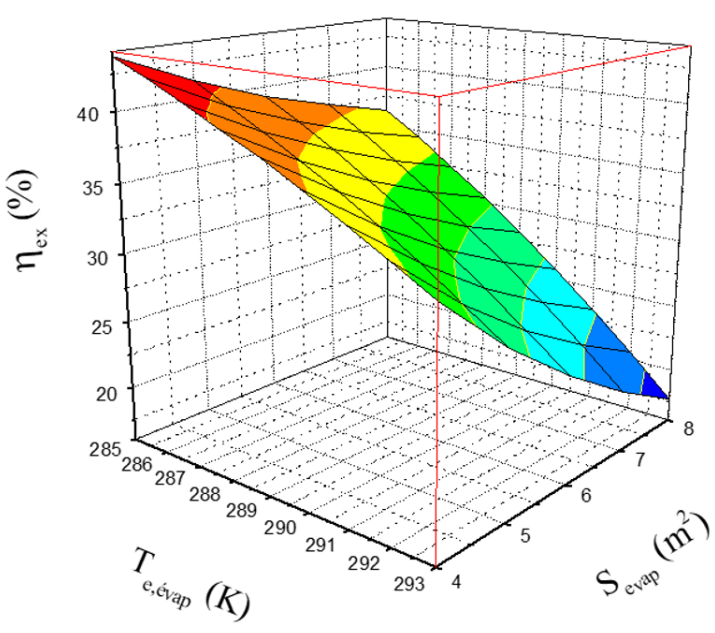

(c)

Fig. 3: Combined influence of the air temperature at the evaporator inlet and the condenser surface on: (a): $C O P$, (b): $\Delta E_{e x}, t,(\mathrm{c}): \eta_{e x}$

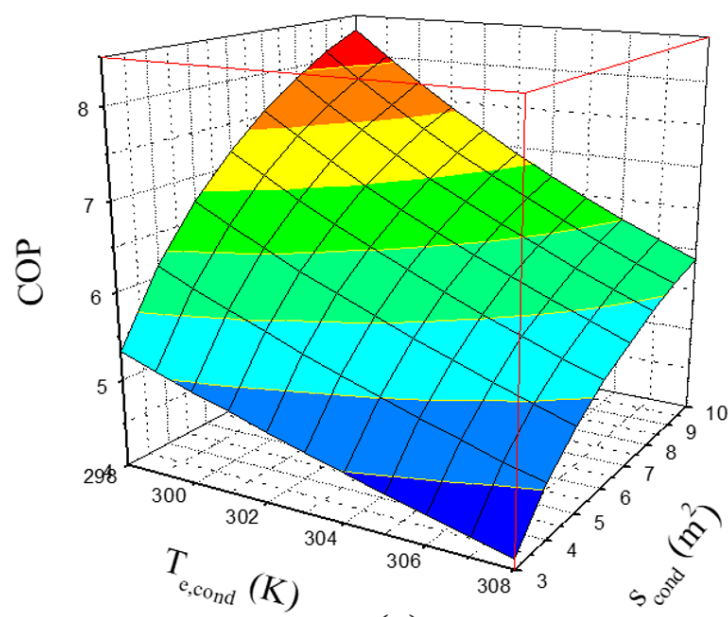

(a) 


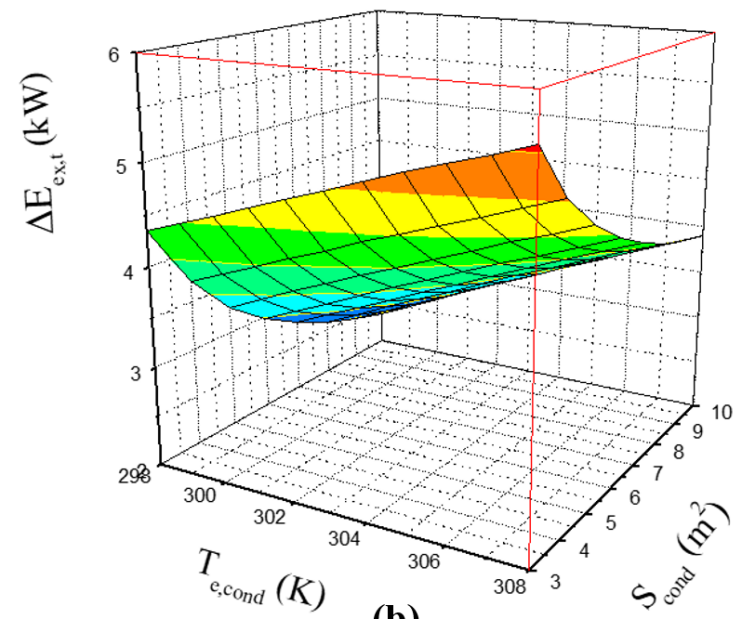

(b)

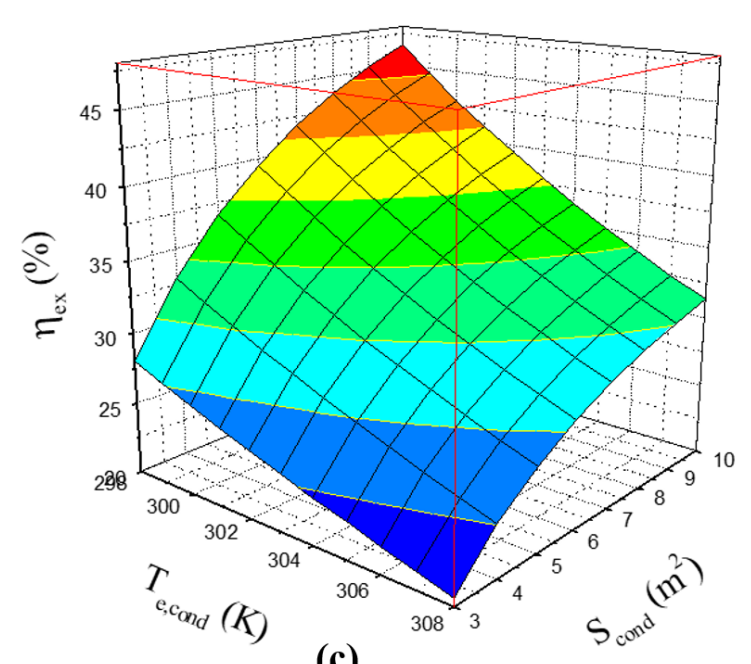

(c)

Fig. 4: Combined influence of the water temperature at the condenser inlet and the condenser surface on: (a): $C O P$, (b): $\Delta E_{e x}, t,(\mathrm{c}): \eta_{e x}$.

Table 1: Simulation parameters

\begin{tabular}{ll}
\hline Condenser & \\
Area, $\mathrm{m}^{2}$ & $3.0-10.0$ \\
Mass flow of seawater, $\mathrm{kg} / \mathrm{s}$ & 3.0 \\
Specific heat of seawater, KJ/kg. K & 4.002 \\
Evaporator & \\
Area, $\mathrm{m}^{2}$ & $4.0-8.0$ \\
Mass air flow, $\mathrm{kg} / \mathrm{s}$ & 6.6 \\
Specific heat of the air, KJ/Kg. K & 1.006 \\
Compressor & \\
Displaced volume, $\mathrm{m}^{3} / \mathrm{s}$ & 0.015 \\
\hline
\end{tabular}

\section{Conclusion}

In this study a thermodynamic modeling of a marine refrigeration machine using ammonia as a refrigerant was presented. The machine in question operates according to a cycle with a single compression stage in which the sub-cooling of the liquid before expansion and the superheating of the vapors before compression are carried out in a recovery exchanger. The results showed that the performance of the machine increases as the temperature of the air entering the evaporator increases. On the other hand, an increase in the temperature of the sea water decreases this performance. In addition, the increased surfaces of the heat exchangers (condenser and evaporator) increase the performance of the machine. In addition, it is observed that the exergy parameters may in some cases not agree with the COP. The challenge which now remains in the industrial field is to find suitable equipment to generalize the use of R717 ammonia as a refrigerant, because it sometimes works with operating pressures different from those of other refrigerants. Our outlook for the future is to expand the use of ammonia as a refrigerant in industrial and domestic refrigeration, because it is efficient and does not create a greenhouse effect.

\section{Acknowledgement}

I extend my thanks and appreciation to each author for their efforts in this manuscript.

\section{Author's Contributions}

Mawhoub SOUBIH: Participated in all thermal calculations and simulation, data-analysis and interpretation and writing of the manuscript.

Dahmane Mouloud: Participated in correction of the document.

Zahaf Samir: Participate in sending the document, correcting all errors in it, and rewriting the document according to the journal template.

Benkhettab Mohamed: Participated in correction of the document.

\section{Ethics}

This article is original and contains unpublished material. The corresponding author confirms that all of the other authors have read and approved the manuscript and no ethical issues involved

\section{References}

Aisbett, E. K., \& Pham, Q. T. (1998). Natural replacements for ozone-depleting refrigerants in eastern and southern Asia. International journal of refrigeration, 21(1), 18-28. doi.org/10.1016/S0140-7007(97)00080-7

Getu, H. M., \& Bansal, P. K. (2008). Thermodynamic analysis of an R744-R717 cascade refrigeration system. International journal of refrigeration, 31(1), 45-54. doi.org/10.1016/j.ijrefrig.2007.06.014 
Kortitsen, E., \& Kristensen, A. P. R. (1998). Ammonia high pressure heat pumps in food refrigeration applications. International journal of refrigeration, 21(3), 212-218. doi.org/10.1016/S0140-7007(98)00012-7

Majgaonkar A. S. (2008). "Refrigeration for ships", ASHRAE Journal, 2008, 50, 50-58

Ouadha, A., Haddad, C., En-Nacer, M., \& Imine, O. (2007, August). Performance comparison of cascade and two-stage refrigeration cycles using natural refrigerants. In The 22nd International Congress of Refrigeration (pp. 21-26).
Palm, B. (2008). Ammonia in low capacity refrigeration and heat pump systems. International journal of refrigeration, 31(4), 709-715. doi.org/10.1016/j.ijrefrig.2007.12.006

Pearson, A. (2008). Refrigeration with ammonia. International journal of refrigeration, 31(4), 545-551. doi.org/10.1016/j.jirefrig.2007.11.011

Stera, A. C. (1994). Utilisation de l'ammoniac en marine. Revue générale du froid (1935), 84(9), 30-31. https://pascal-

francis.inist.fr/vibad/index.php?action=getRecordDetai 1\&idt=3462165 